therefore suggests first, that the Electricity Commissioners should be given powers to draw up regulations in respect of any apparatus or plant, new and existing, which may cause interference with radio reception; and secondly, that the Post Office should be given powers to enforce these regulations. No special difficulty is seen in applying the regulations to new apparatus, and the cost of the mitigating devices is in most cases only a small percentage of that of the appliance. In the case of appliances already in use, the question of who is to meet the cost of suppression is considered to be a matter for the legislature to decide.
The report shows that a somewhat complicated subject has been explored in a very thorough and fruitful manner by the co-operative effort of representatives of all the parties concerned, and the conclusions reached and recommendations made will, in general, be regarded as very satisfactory. It will probably be some considerable time before legislation and regulations can be made effective, and in the meantime, the Institution of Electrical Engineers appeals to the general public to continue the goodwill on which the Post Office has been enabled to build up its very successful work in suppressing interference with broadcasting.

\title{
The Medical Curriculum
}

$\mathrm{A}^{\mathrm{T}}$ T a meeting on May 29, the General Medical Council adopted certain resolutions in regard to professional education. These will come into operation on January 1, 1938, and include the following :

In the pre-registration requirements, it is laid down that every applicant for registration as a student by the Council or for admission to the medical curriculum proper should have passed (a), a recognised preliminary examination in general education as laid down in the Regulations of the Council ; and, in addition (b), an examination or examinations conducted or recognized by one of the licensing bodies.

The subjects to be included under $(b)$ are :

(1) One or two subjects of general education, other than chemistry, physics, or biology, at a standard higher than that of the preliminary examination, for those who have received their instruction in these subjects before entering universities, university colleges, or medical schools.

(2) Chemistry (theoretical and practical), the elementary principles of general and physical chemistry, and of the chemical combination of elements, including carbon.

(3) Physics (theoretical and practical), the elementary mechanics of solids and fluids, the elements of heat, light, sound, electricity and magnetism.

The examination in biology (theoretical and practical) may be taken either before or after registration as a student.

It will be remembered that about a year ago a conference of representatives nominated by the
Universities of Oxford, Cambridge and London; the Royal College of Physicians of London; the Royal College of Surgeons of England and the Society of Apothecaries of London published a report on the medical curriculum (see Nature, July 20,1935 , p. 90 , and Nov. 2, p. 706). The report stressed the need for a continuance of the general education of intending medical students of postSchool Certificate stage, and therefore recommended that "the Licensing Bodies consider the possibility of allowing and encouraging exemption from the Ist M.B. examination by means of a Higher School Certificate Examination conducted by any recognised Examining Body in which, in addition to the three principal scientific subjects, a subsidiary non-scientific subject be taken".

The Higher School Certificate Examination is the normal objective of the post-School Certificate student in public and secondary schools, and if the licensing bodies would recognize for the purpose of exemption from the second examination stated in pre-registration requirements those subjects in which a student has passed a Higher School Certificate Examination (chemistry, physics, biology to 'Group' standard and non-scientific subjects to 'Subsidiary' standard), they will impart to the Higher School Certificate examination a value which has been questioned in the past by so many intending medical students. The recognition would also lead to greater uniformity in the education of post-School Certificate students in the schools, and would go a long way towards removing the evil of segregation of intending medical students from the rest of the school. 